\title{
CARTA DO LEITOR
}

Rio de Janeiro, 01 de abril de 1987

Luiz David Castiel, em recente editorial (Gerra é doença: a questão da paz e os profissionais da saúde coletiva no Brasil - Cadernos de Saúde Pública, RJ, 1 (4): $397-399,1985)$, referiu-se ao movimento pela paz e, com muita propriedade, à "responsabilidade dos trabalhadores em Saúde Coletiva na tarefa de buscar formas de mobiliza. ção e participação numa causa que não admite contempo. rização".

Castiel propõe que essa participação se dê através do "engajamento nos movimentos pacifistas já organizados no pais". Estou de acordo, mas considero que contribuições mais específicas podem ser também de grande importância.

$\mathrm{O}$ debate sobre os aspectos médicos do problema tem aparecido com frequêencia crescente nos meios acadêmicos (cf. Special Report: New Perspectives on the Medical Consequences of Nuclear War. The New England Journal of Medicine, 315 (14): 905-912, 1986). Em termos organizativos, foram iniciadas em 1980 as atividades da International Physicians for the Prevention of Nuclear War (IPPNW), fundada por médicos americanos e soviéticos, e que já congrega, atualmente, 150000 médicos em 49 países.

Em 1983, a IPPNW promoveu, em âmbito mundial, a realização de um abaixo-assinado, enviado aos dirigentes dos países que possuem armas nucleares, onde se afirmava que "a ameaça da guerra nuclear é o maior desafio à saúde e a sobrevivência que a humanidade jamais enfrentou. Como médicos, acreditamos que a guerra nuclear seria a epidemia final".

O 70. Congresso Mundial da IPPNW será realizado em Moscou, entre 29 de maio e 1 ? de junho de 1987. Ao mesmo tempo, está em curso a estruturação da Sociedade Brasileira de Médicos pela Prevenção da Guerra Nuclear, filiada à IPPNW, que prevê o funcionamento de núcleos estaduais.

Colocamo-nos à disposição, para outras informações, nos telefones 284-8249 (Instituto de Medicina Social/UERJ) e 242-9080 (Divisão de Epidemiologia/Instituto Nacional de Câncer).

Atenciosamente,

\author{
EDUARDO FAERSTEIN \\ Divisão de Epidemiologia \\ $\mathrm{CPRH} \cdot \mathrm{INCa}$
}

Cadernos de Saúde Pública, R.J., (3):390-395, jul/set, 1986. 